\title{
The efficacy and safety of prophylactic closure for a large mucosal defect after colorectal endoscopic submucosal dissection
}

\author{
SHINTARO FUJIHARA ${ }^{1}$, HIROHITO MORI ${ }^{1}$, HIDEKI KOBARA ${ }^{1}$, NORIKO NISHIYAMA ${ }^{1}$, \\ MITSUYOSHI KOBAYASHI ${ }^{1}$, KAZI RAFIQ ${ }^{2}$ and TSUTOMU MASAKI $^{1}$ \\ Departments of ${ }^{1}$ Gastroenterology and Neurology and ${ }^{2}$ Pharmacology, \\ Faculty of Medicine, Kagawa University, Kagawa 761-0793, Japan
}

Received February 11, 2013; Accepted April 22, 2013

DOI: $10.3892 /$ or.2013.2466

\begin{abstract}
Endoscopic submucosal dissection (ESD) is not a common treatment for colorectal neoplasms because of its technical difficulties and has a higher incidence of complication. In particular, perforation is one of the severe complications and these patients require surgical intervention. However, whether prophylactic closure after colorectal ESD prevents perforation and other complications is not known. In the present study, we assessed the efficacy and safety of prophylactic closure for a large mucosal defect after colorectal ESD using a conventional clip and over-the-scope clip (OTSC) system. From April 2010 to December 2012, 68 patients with colorectal tumors were treated with ESD. The prohylactic closure was indicated for patients with excessive coagulation in the muscularis propria or larger resection size. The closure group reduced the peritoneal inflammatory reaction and abdominal symptoms without increasing complications. The closure group also had a significantly lower WBC count (post operative day 1), CRP (post operative day 4) and abdominal pain after colorectal ESD compared to the non-closure group. Perforation occurred in 1 case, and postoperative bleeding in 2 cases, with only 1 bleeding case needing an emergency endoscopy in the non-closure group. One perforation case needed emergency surgery because the endoscopic treatment was ineffective. Without increasing adverse effects, the prophylactic closure efficiently reduced the inflammatory reaction and abdominal symptoms of colorectal ESD in patients with large superficial colorectal neoplasms.
\end{abstract}

Correspondence to: Dr Tsutomu Masaki, Department of Gastroenterology and Neurology, Faculty of Medicine, Kagawa University, 1750-1 Ikenobe, Miki-cho, Kita-gun, Kagawa 761-0793, Japan

E-mail: tmasaki@med.kagawa-u.ac.jp

Abbreviations: ESD, endoscopic submucosal dissection; EMR, endoscopic mucosal resection; LST, lateral spreading tumor; CRP, C-reactive protein; WBC, white blood cell; OTSC, over-the-scope clip system

Key words: endoscopic submucosal dissection, colorectal cancer, perforation, the over-the-scope clip system, prophylactic closure

\section{Introduction}

Endoscopic submucosal dissection (ESD) for the treatment of large gastric superficial neoplasms is increasing due to the high en bloc resection rate. However, colorectal ESD is not widely used to treat large superficial colorectal neoplasms world-wide presumably because of its technically difficulties and higher incidence of complications (1). In particular, perforation is the most severe complication after colorectal ESD and was reported $1.4-10.4 \%$ in previous studies $(2,3)$. The risk of perforation after ESD is higher than after EMR, although most were small in size and successfully treated by conventional clips. In contrast, delayed perforation has been reported as a serious complication after ESD and it requires emergency surgical treatment. The rate of delayed perforation is reported to be $0.3-0.7 \%(4,5)$. The reasons for delayed perforation are unknown, but it is reported to be related to excessive coagulation in the muscularis propria (2). In addition, one of the reasons for the high rate of perforations and peritoneal inflammation is the thinness of the colorectal wall compared with the gastric wall, resulting in transmural electrocautery injury, and a large resection size may also contribute to complications, including delayed bleeding and perforation as well as inflammation without perforation (6,7). However, patients experienced abdominal pain, fever, leukocytosis, major signs of peritoneal inflammation in the absence of frank perforation, which occurs after colorectal ESD $(8,24)$. These symptoms are similar to postpolypectomy electrocoagulation syndrome (also known as postpolypectomy syndrome and transmural burn syndrome). Many reports have revealed perforations and postoperative hemorrhages, but peritoneal inflammation without perforation and transmural burn syndrome after colorectal ESD are not well described. In this regard, whether prophylactic closure after colorectal ESD prevents perforation and other complications is not known. Therefore, in the present study we assessed the effectiveness of prophylactic closure for a large mucosal defect after colorectal ESD using a conventional clip and OTSC.

\section{Materials and methods}

The present study was designed as a retrospective cohort study, conducted in the Endoscopy Unit at Kagawa University 


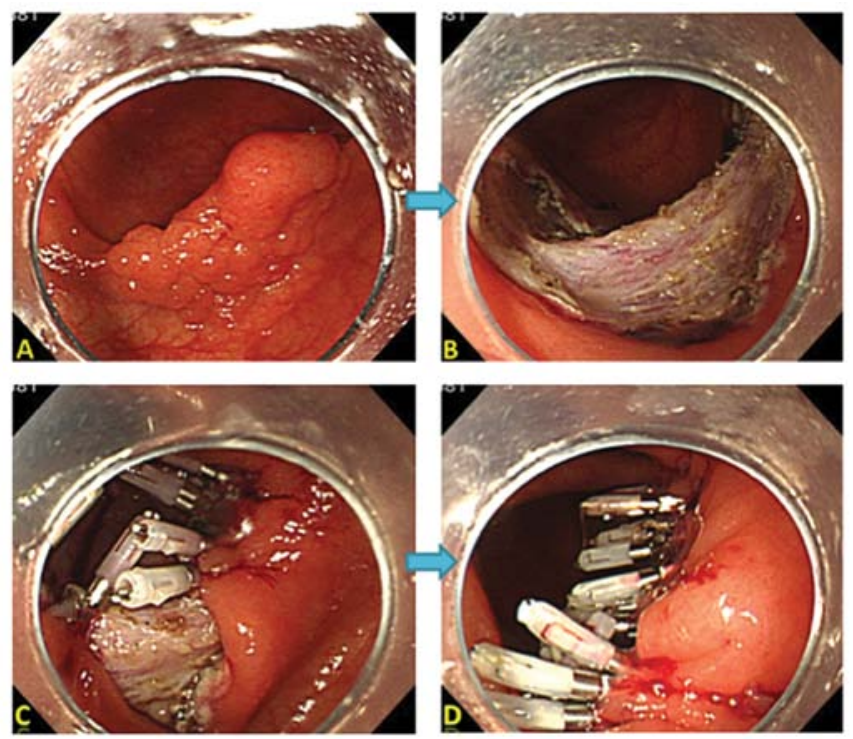

Figure 1. Endoscopic closure for an artificial ulcer with conventional clips. (A) A large granular type laterally spreading tumor measuring $35 \mathrm{~mm}$ in diameter located in the ascending colon. (B) A large mucosal defect after colorectal ESD. (C and D) Complete closure was performed, but this technique requires more time. Completely closing a large mucosal defect (size $>30 \mathrm{~mm}$ ) is difficult.

Hospital during the period April 2010 to December 2012. A total of 77 patients were referred to our hospital during this period, out of whom 68 patients with superficial colorectal neoplasm (mean tumor size of $35.4 \mathrm{~mm}$ ) were enrolled and assigned to undergo colorectal ESD. After successful colorectal ESD, closure of artificial wound were achieved by conventional clips (EZ Clip; Olympus Co., Tokyo, Japan) for small mucosal defects (tumor size $<30 \mathrm{~mm}$ ) and over-the-scope clip system (OTSC, Ovesco Endoscopy, Tübingen, Germany) for: i) a large mucosal defect (tumor size $>30 \mathrm{~mm}$ ); ii) flexure of the colon; and iii) an inability to close with conventional clips (Figs. 1 and 2). For OTSC system, we used $9 \mathrm{~mm}$ diameter and $6 \mathrm{~mm}$ depth of OTSC caps with atraumatic blunt teeth.

The patient's exclusion criteria for the present study were as follows: i) lesions that could result in en bloc resection by EMR; ii) lesions located in the anal canal or at the appendix; iii) tumor size $>70 \mathrm{~mm}$; iv) severe organ failure; v) undergoing anticoagulant therapy; and vi) an inability to obtain written informed consent. Before colorectal ESD individual written informed consent were obtained from all patients.

All ESD procedures were performed by three experienced endoscopists (H.M, H.K and M.K) in this unit.

The study protocol was approved by the Ethics Committee of the Kagawa University. The present study has been registered in the University Hospital Medical Information Network Clinical Trial Registry (UMIN-CTR) as no. UMIN000007315.

Participants. The depth of invasion was limited to mucosal or SM1, as estimated endoscopically and by magnification using chromoendoscopy in most cases (9). Based on extensive clinicopathological analyses (10-12), we defined the indications for ESD (13) as non-granular type LSTs $>20 \mathrm{~mm}$ and granular type LSTs $>30 \mathrm{~mm}$ because both have a higher SM invasion rate and are difficult to treat even by piecemeal EMR $(10,12)$.
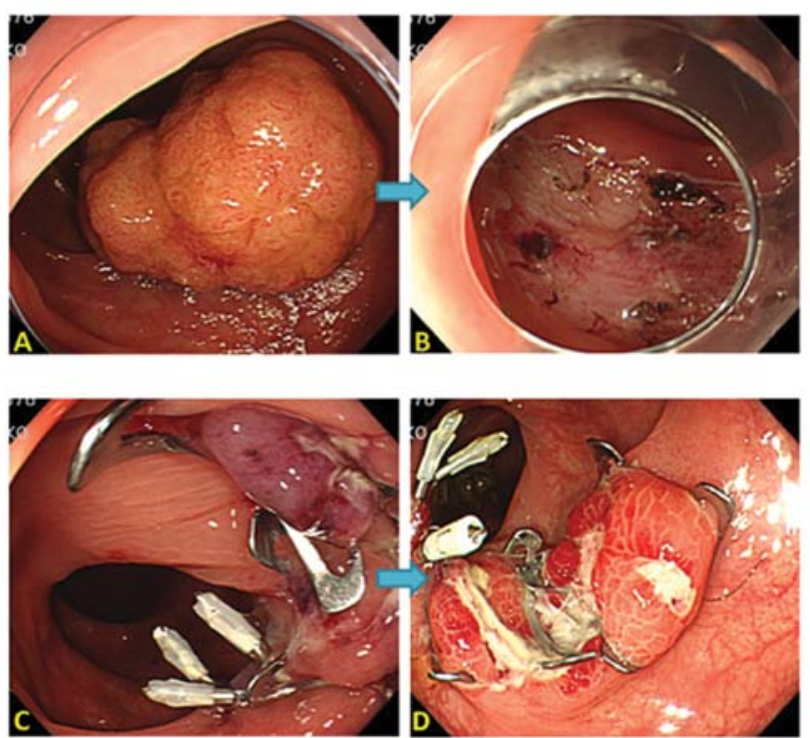

Figure 2. Endoscopic closure for an artificial ulcer with conventional clips and the OTSC system. (A) A large tumor measuring $35 \mathrm{~mm}$ in diameter located in the ascending colon. (B) A large mucosal defect after colorectal ESD. (C) Complete closure was performed using conventional clips and the OTSC system. (D) Postoperative day 7, endoscopic view.

Large villous tumors and intramucosal lesions, recurrent lesions and residual mucosal lesions that showed a non-lifting sign $(14,15)$ after EMR were also potential candidates for ESD, with the final decision made by each individual endoscopist.

Clinicopathological characteristics and histological assessment. The tumor types were classified according to the Paris classification (16) and Kudo's classification (17) as follows: type 0 -I (protruded) and two subtypes of laterally spreading tumors (LSTs). The two subtypes of LSTs were either granular (LST-G) or non-granular (LST-NG). The extent of the tumor was determined by differences in the color, height, morphological features and pit patterns between the neoplastic and non-neoplastic mucosa. The tumor depth was assessed using morphological features. Tumors that showed evidence of regions of hardness, irregular nodules, ulceration, or submucosal tumor-like marginal elevation were suspected to be massive $\mathrm{SM}>1,000 \mu \mathrm{m}$ (SM2 or deeper).

The histological classification was performed according to the Vienna classification of gastrointestinal epithelial neoplasia $(18,19)$. The extension of tumor cells to the resected margin was evaluated as following: complete resection (R0); with the lateral and basal resection margins free of tumor (where en bloc resection is essential), incomplete resection (R1); when the tumor extended into the lateral or basal margins, or not evaluable ( $\mathrm{Rx}$ ); when we were unable to evaluate the margins.

Premedication before colorectal ESD. The patients were given a low-fiber diet during the day before ESD and were prescribed $24 \mathrm{mg}$ of sennoside (Pursennid; Novartis Pharma, Tokyo, Japan) the night before ESD. In the morning before ESD, Niflec (Ajinomoto Pharmaceuticals, Tokyo, Japan) with $2,000 \mathrm{ml}$ of water was used to clean the bowel. An intravenous injection was administered immediately before the proce- 
dure, which comprised $20 \mathrm{mg}$ of scopolamine butylbromide (Buscopan; Nippon Boehringer Ingelheim Co., Ltd., Tokyo, Japan) or $1 \mathrm{mg}$ of glucagon (Glucagon G Novo; Eisai, Tokyo, Japan) as well as $15 \mathrm{mg}$ of pentazocine (Pentazin; Daiichi Sankyo, Tokyo, Japan) and $2.5 \mathrm{mg}$ of midazolam (Dormicum; Astellas Pharma, Tokyo, Japan). Throughout the procedure, $1.25 \mathrm{mg}$ midazolam was administered as required.

ESD technique. All procedures were performed using a standard colonoscope (EVIS PCF-Q260AI or GIF H260Z, Olympus Medical Systems Co., Tokyo, Japan) and carbon dioxide. The disposable distal attachment (D-201-13404; Olympus) was mounted onto the tip of the endoscope. A VIO 300D (Erbe Elektromedizin GmbH, Tübingen, Germany) or ICC200 (Erbe Elektromedizin) was used as a power source for the electrical cutting and coagulation. During the colorectal ESD technique in the present study we mainly used the Dual knife (Olympus Medical Systems) and the insulated tipped (IT) knife (Olympus Medical Systems). A mixture of 1\% hyaluronic acid (MucoUp; Johnson \& Johnson K.K., Tokyo, Japan) and 10\% glycerin (Glyceol; Chugai Pharmaceutical Co., Tokyo, Japan) was used as the injection liquid.

Treatment protocol. The patients were admitted to our unit the day before the ESD. After colorectal ESD procedure the patients had a 2-day fasting period, and were discharged from the hospital 7 days after the colorectal ESD. We checked the laboratory data at postoperative day 1 . If WBC count and CRP were elevated, we checked the laboratory test at postoperative day 4 as well. All patients were prescribed cefmetazole (Cefmetazon; Daiichi Sankyo) for 3 days after colorectal ESD. After dischared from our unit the patients were followed up for 30 days after the procedure as outpatient visits to record late adverse events.

Measured outcomes. Postpolypectomy syndrome and transmural burn syndrome are characterized by a local peritoneal inflammation in the absence of frank perforation, which occurs after colorectal ESD. To assess the local peritoneal inflammation, the primary end point measured for the patient reactions, such as abdominal pain, recorded initial visual analog scale (VAS) pain score, increases in WBC count, C-reactive protein levels and body temperature.

We compared the 2 groups with respect to visual analogue scale (VAS) score $24 \mathrm{~h}$ after colorectal ESD. VAS score was determined based on a scale of $0-10$ with 0 equal to no pain and 10 equal to the worse pain imaginable. Abdominal pain was defined as moderate or greater pain in the region of the ESD site (VAS $\geq 4$ ). The body temperature readings were recorded regularly for all patients during hospitalization.

Adverse events, postoperative bleeding and perforation after colorectal ESD were evaluated as secondary end points. Postoperative bleeding was defined as clinical evidence of bleeding manifested by melena or hematochezia from 0 to 14 days after the procedure that required endoscopic hemostasis. Perforation during an ESD procedure was defined as immediate, and delayed perforation was defined as occurring after the completion of the ESD procedure.

The number of clips, closure completion rate, closure procedure time, and closure-related complications, including patient reactions such as abdominal pain and increases in white blood cell count, C-reactive protein levels, and body temperature were counted by recorded video after the procedure and were also evaluated as secondary end points.

Statistical analysis. The absolute and relative frequencies of qualitative variables were calculated for each group. Continuous variables were expressed as the median and range. The continuous variables were compared using the Student's t-test if normally distributed or the Wilcoxon test if not normally distributed. Pearson's Chi-square test or Fisher's exact test was used to analyze the categorical data to compare the proportions. All P-values were two-tailed, with $\mathrm{P}<0.05$ being defined as statistically significant. The data analysis was conducted using JMP version 9.0 (SAS Institute Inc., Cary, NC, USA).

\section{Results}

Between April 2010 and December 2012, we performed colorectal ESD for a total of 77 patients with superficial colorectal neoplasm, out of which 68 patients were referred to our hospital from other hospital. A total of 68 patients (39 men and 29 women) and mean tumor size were $35.4 \mathrm{~mm}, 68$ patients with superficial colorectal neoplasms were enrolled in the present study and were assigned to undergo colorectal ESD with or without endoscopic closure group. The remaining 9 patients were excluded from the present study due to following reasons: tumor size $>70 \mathrm{~mm}(\mathrm{n}=5)$; when another endoscopists rather than ours was assigned to perform the colorectal ESD $(n=3)$; other reasons (inability to obtain written informed consent) ( $\mathrm{n}=1)$.

The patient characteristics and tumor clinicopathological features are summarized in Table I and were not significantly different among the closure and non-closure group.

Tables II and III summarize the closure technique results in the closure group as well as the difference between conventional clips and OTSC clips using group. The closure group had a longer operation time; however, this difference was not significantly different among the groups. We used conventional clips in 18 cases, and OTSC system in 9 cases for closing a large mucosal defect after colorectal ESD. The mean closure procedure time is significantly shorter in the conventional clips using group compared to OTSC using group. The resected tumor diameter tends to be larger in the OTSC using group than in the conventional clip using group with no significant differences. Complications related to prophylactic closure did not occur in either group.

The outcome data are summarized in Table IV. Abdominal pain was present in 1 patient $(3.7 \%)$ in the closure group, whereas, abdominal pain was present in 12 patients $(29.3 \%)$ in the non-closure group. The closure group had a significantly lower ratio of abdominal pain after colorectal ESD compared to non-closure group. However, the closure group had a lower WBC count (post operative day 1) and C-reaction protein levels (post operative day 4) with significant difference between the two groups.

The median hospitalization period was similar among the groups. In the non-closure group, perforation occurred in one case and postoperative bleeding occurred in two cases, of 
Table I. Patient characteristics.

\begin{tabular}{|c|c|c|c|}
\hline \multirow[b]{2}{*}{ Characteristics } & \multicolumn{2}{|c|}{ Groups } & \multirow[b]{2}{*}{ P-value } \\
\hline & $\begin{array}{c}\text { Closure } \\
(n=27\end{array}$ & $\begin{array}{l}\text { Non-closure } \\
\quad(n=41)\end{array}$ & \\
\hline \multicolumn{4}{|l|}{ Patient } \\
\hline Age, mean (range), years & $67(37-88)$ & $71(51-87)$ & 0.6513 \\
\hline Gender, male/female & $18: 9$ & $21: 20$ & 0.2076 \\
\hline \multicolumn{4}{|l|}{ Tumor } \\
\hline Diameter, mean (range), mm & $32(16-55)$ & $35(18-70)$ & 0.2188 \\
\hline Location, $\mathrm{n}$ & & & 0.2402 \\
\hline Cecum & 8 & 5 & \\
\hline Ascending colon & 3 & 9 & \\
\hline Transverse colon & 1 & 4 & \\
\hline Descending colon & 2 & 0 & \\
\hline Sigmoid colon & 6 & 9 & \\
\hline Upper rectum & 3 & 5 & \\
\hline Lower rectum & 4 & 9 & \\
\hline Macroscopic type & & & 0.7857 \\
\hline $\begin{array}{l}\text { Granular type laterally } \\
\text { spreading }\end{array}$ & 15 & 26 & \\
\hline $\begin{array}{l}\text { Non-granular type laterally } \\
\text { spreading }\end{array}$ & 4 & 6 & \\
\hline 0 -Is & 2 & 3 & \\
\hline 0 -Isp & 4 & 2 & \\
\hline Post EMR residual & 1 & 3 & \\
\hline Others & 1 & 1 & \\
\hline Histology & & & 0.1974 \\
\hline Low grade adenoma & 4 & 0 & \\
\hline Moderately grade adenoma & 2 & 1 & \\
\hline High grade adenoma & 7 & 11 & \\
\hline $\begin{array}{l}\text { Well differentiated } \\
\text { adenocarcinoma }\end{array}$ & 10 & 23 & \\
\hline $\begin{array}{l}\text { Moderately differentiated } \\
\text { adenocarcinoma }\end{array}$ & 3 & 4 & \\
\hline Others & 1 & 2 & \\
\hline Depth of invasion & & & 0.8770 \\
\hline Mucosal & 9 & 18 & \\
\hline SM1 & 1 & 3 & \\
\hline SM2 & 3 & 5 & \\
\hline Vessel infiltration, $\mathrm{n}$ & 3 & 3 & 0.3754 \\
\hline Ulcer presentation, $\mathrm{n}$ & 1 & 2 & 0.8157 \\
\hline
\end{tabular}

which one bleeding case underwent an emergency endoscopy. Immediately after colorectal ESD with complete removal one perforation was recognized, and needed emergency surgery because the endoscopic treatment was ineffective. The lesion was LST-NG, and located in the cecum with severe fibrosis. The en bloc R0 resection rate and en bloc curative resection rate were similar between the groups.
Table II. Closure technique results.

Closure technique results

No. of lesions

Technique, conventional clip:OTSC

Closure completion rate, $\mathrm{n}(\%)$

Closure procedure time, median (range), min

Total procedure time, median (range), min

$124.8(60-250)$

Closure related to complication

$\begin{array}{ll}\text { Perforation, n (\%) } & 0 / 27(0) \\ \text { Bleeding, n (\%) } & 0 / 27(0) \\ \text { Stenosis, n }(\%) & 0 / 27(0)\end{array}$

\section{Discussion}

The major complications of colorectal ESD are postoperative perforation and hemorrhage. To standardize the colorectal ESD procedure, decreasing the rate of perforation and other complications are urgently needed. In the present study, in fact, we experienced the development of abdominal pain, fever, leukocytosis and peritoneal inflammation in the absence of a frank perforation. These common clinical complications are also reported by previous studies after colorectal $\operatorname{ESD}(8,25)$. These symptoms are similar to postpolypectomy electrocoagulation syndrome.

The majority of patients after colorectal ESD complain about abdominal pain and tenderness in the region of the ESD site. Some patients have localized abdominal tenderness, rigidity, fever, leukocytosis and tachycardia (20), a symptom complex that closely resembles colonic perforation. Usually patients complained such symptoms within $12 \mathrm{~h}$ after ESD; however, symptoms may appear up to five days after the procedure (21)

Postpolypectomy syndrome and transmural burn syndrome are characterized by a local peritoneal inflammation in the absence of frank perforation, which occurs after colorectal ESD, and they are related to excessive coagulation in the muscularis propria (2) and a large mucosal defect after colorectal ESD. According to previous reports such events occur in $0.5-1.2 \%$ patients undergoing polypectomy $(22,23)$, however, we experienced these events more often after colorectal ESD than after polypectomy and EMR.

In the present study, we had 6 patients (14\%) with moderate and severe peritoneal inflammation, and they experienced a prolonged fasting period, duration of antibiotics administration and hospitalization. In a previous report, the mean amount of C-reactive protein 2 days after the ESD was $5.82 \pm 12.10 \mathrm{mg} / \mathrm{l}$ in cases with perforation and $1.27 \pm 2.00 \mathrm{mg} / \mathrm{l}$ in cases without perforation (8). These results suggesting that the endoscopic closure was more effective in preventing inflammatory reactions.

Although various closure devices and methods have been reported for the closure of artificial wound after ESD $(25,26)$, it still has greater technical difficulty. In addition, we could not close large mucosal defects (tumor size $>35 \mathrm{~mm}$ ) 
Table III. Conventional clips and OTSC technique results.

\begin{tabular}{|c|c|c|c|}
\hline & Conventional clips $(n=18)$ & OTSCs $(n=9)$ & P-value \\
\hline Using OTSC and clip no., median (range) & $8(4-12)$ & $1(1-3)$ & $<0.0001$ \\
\hline Closure procedure time, median (range) & $11.1(8.3-30)$ & $25.3(8.5-37.7)$ & 0.0013 \\
\hline Resected specimen diameter, median (range) & $28(16-45)$ & $32(20-55)$ & 0.0641 \\
\hline
\end{tabular}

Table IV. Patient responses and measurements.

\begin{tabular}{|c|c|c|c|}
\hline Findings & Closure group & Non-closure group & P-value \\
\hline No. of lesions & 27 & 41 & \\
\hline Abdominal pain, n (\%) & $1 / 27(3.7)$ & $12 / 41(24.4)$ & 0.0046 \\
\hline White blood cell count (POD1), median (range) & $6170(1780-11860)$ & $7320(3960-14190)$ & 0.0421 \\
\hline White blood cell count (POD4), median (range) & $4750(2210-7870)$ & $5335(2950-14670)$ & 0.1258 \\
\hline C-reactive protein (POD1), median (range) & $0.45(0.03-3.28)$ & $0.43(0.02-5.35)$ & 0.5175 \\
\hline C-reactive protein (POD4), median (range) & $0.17(0.02-2.07)$ & $1.01(0.01-21.86)$ & 0.0456 \\
\hline Maximum body temperature, median (range) & $36.9(36.4-38.5)$ & $37.1(36.5-38.9)$ & 0.0341 \\
\hline Postoperative bleeding, n (\%) & $0 / 27(0)$ & $2 / 41(4.9)$ & 0.1725 \\
\hline Perforation, n (\%) & $0 / 27(0)$ & $1 / 41(2.4)$ & 0.4136 \\
\hline Hospitalization, mean (range) & $8(7-11)$ & $8(5-19)$ & 0.6483 \\
\hline Total procedure time, median (range), min & $128(60-250)$ & $105(45-240)$ & 0.3330 \\
\hline en bloc $\mathrm{R} 0$ resection, $\mathrm{n}(\%)$ & $26 / 27(96)$ & $41 / 41(100)$ & 0.7551 \\
\hline en bloc curative resection, $\mathrm{n}(\%)$ & $23 / 27(85)$ & $36 / 41(88)$ & 0.7551 \\
\hline
\end{tabular}

using only conventional clips. Because of the limitations to commercially available clips, is a low closure force that is suboptimal for compressing scarred and hardened tissues (27). The over-the-scope clip system offers the advantage of capturing nitinol clip loaded at the tip of the endoscope which can capture leaks and fistula orifices and compress them constantly until healed (28).

An over-the-scope clip (OTSC) (Ovesco Endoscop) has been developed for the closure of small mural defects and bleeding ulcers (29). The OTSC produces more durable closure than standard endoclips (30) because of its ability to grasp more tissue, include the entire thickness of the visceral wall and apply a greater compressive force. We used the overthe-scope clip system (OTSC, Ovesco Endoscopy) for: i) a large mucosal defect (tumor size $>30 \mathrm{~mm}$ ); ii) flexure of the colon; iii) excessive coagulation in the muscularis propria; and iv) an inability to close with conventional clips. The closure group with OTSC system required more time for the closure compared with the conventional group. The reason is that in 5 cases the tumor was located at a sharp bend in the sigmoid colon, difficult to close a large mucosal defect using a Twin Grasper (Ovesco Endoscopy). Complications related to the use of OTSC are perforation (31), mucosal laceration (32), postprocedural pain (32), which did not occur in closure groups of the present study.

The present study shows that endoscopic closure using conventional clips and the OTSC system was effective in preventing local peritoneal inflammation and in relieving the patient's abdominal symptoms after colorectal ESD. However, the present study did not demonstrate that endoscopic closure decreased the occurrence of perforation and postoperative bleeding.

The present study has some limitations. First, the small patient sample size was a limiting factor. Therefore, we need more prospective studies involving larger numbers of patients to establish the effectiveness of the endoscopic closure. Second, this study was not a prospective randomized study that directly compared the closure group with the non-closure group. A prospective randomized study is needed to confirm the efficacy and safety of this method in the near future. The third limitation of the present study was the non-standardization of polyps removed by three experts.

In conclusion, the prophylactic closure efficiently reduced the inflammatory reaction and abdominal symptoms of colorectal ESD in patients with large superficial colorectal neoplasms without increasing adverse effects.

\section{References}

1. Hurlstone DP, Sanders DS, Cross SS, et al: Colonoscopic resection of lateral spreading tumours: a prospective analysis of endoscopic mucosal resection. Gut 53: 1334-1339, 2004.

2. Yoshida N, Yagi N, Naito Y, et al: Safe procedure in endoscopic submucosal dissection for colorectal tumors focused on preventing complications. World J Gastroenterol 16: 1688-1695, 2010.

3. Raju GS, Saito Y, Matsuda T, et al: Endoscopic management of colonoscopic perforations. Gastrointest Endosc 74: 1380-1388, 2011. 
4. Fujishiro M, Yahagi N, Kakushima N, et al: Outcomes of endoscopic submucosal dissection for colorectal epithelial neoplasms in 200 consecutive cases. Clin Gastroenterol Hepatol 5: 678-683, 2007.

5. Isomoto H,Nishiyama H, Yamaguchi N, et al: Clinicopathological factors associated with clinical outcomes of endoscopic submucosal dissection for colorectal epithelial neoplasms. Endoscopy 41: 679-683, 2009

6. Anderson ML, Pasha TM and Leighton JA: Endoscopic perforation of the colon: lessons from a 10-year study. Am J Gastroenterol 95: 3418-3422, 2000.

7. Onogi F, Araki H, Ibuka T, et al: 'Transmural air leak': a computed tomographic finding following endoscopic submucosal dissection of gastric tumors. Endoscopy 42: 441-447, 2010.

8. Yoshida N, Kanemasa K, Sakai K, et al: Experience of endoscopic submucosal dissection (ESD) to colorectal tumor-especially about clinical course of cases with perforation (Japanese literature with English abstract). Gastroenterol Endosc 50: 1472-1483, 2008.

9. Kashida $\mathrm{H}$ and Kudo SE: Early colorectal cancer: concept, diagnosis, and management. Int J Clin Oncol 11: 1-8, 2006.

10. Saito Y,Fujii T, Kondo H, et al: Endoscopic treatment for laterally spreading tumors in the colon. Endoscopy 33: 682-686, 2001.

11. Tanaka S, Haruma K, Oka S, et al: Clinicopathologic features and endoscopic treatment of superficially spreading colorectal neoplasms larger than $20 \mathrm{~mm}$. Gastrointest Endosc 54: 62-66, 2001.

12. Uraoka T, Saito Y, Matsuda T, et al: Endoscopic indications for endoscopic mucosal resection of laterally spreading tumors in the colorectum. Gut 55: 1592-1597, 2006.

13. Saito Y, Uraoka T, Matsuda T, et al: Endoscopic treatment of large superficial colorectal tumors: a case series of 200 endoscopic submucosal dissections (with video). Gastrointest Endosc 66: 966-973, 2007

14. Ishiguro A, Uno Y, Ishiguro Y, et al: Correlation of lifting versus non-lifting and microscopic depth of invasion in early colorectal cancer. Gastrointest Endosc 50: 329-333, 1999.

15. Kobayashi N, Saito Y, Sano Y, et al: Determining the treatment strategy for colorectal neoplastic lesions: endoscopic assessment or the non-lifting sign for diagnosing invasion depth? Endoscopy 39: 701-705, 2007.

16. Participants in the Paris workshop: The Paris endoscopic classification of superficial neoplastic lesions: esophagus, stomach, and colon: November 30 to December 1, 2002. Gastrointest Endosc 58: S3-S43, 2003.

17. Kudo S, Lambert R, Allen IJ, et al: Nonpolypoid neoplastic lesions of the colorectal mucosa. Gastrointest Endosc 68: S3-S47, 2008
18. Schlemper RJ, Riddell RH, Kato Y, et al: The Vienna classification of gastrointestinal epithelial neoplasia. Gut 47: 251-255, 2000.

19. Dixon MF: Gastrointestinal epithelial neoplasia: Vienna revisited. Gut 51: 130-131, 2002.

20. Waye JD: The postpolypectomy coagulation syndrome. Gastrointest Endosc 27: 184, 1981.

21. Waye JD, Lewis BS and Yessayan S: Colonoscopy: a prospective report of complications. J Clin Gastroenterol 15: 347-351, 1992.

22. Waye JD, Kahn O and Auerbach ME: Complications of colonoscopy and flexible sigmoidoscopy. Gastrointest Endosc Clin N Am 6: 343-377, 1996.

23. Nelson DB, McQuaid KR, Bond JH, et al: Procedural success and complications of large-scale screening colonoscopy. Gastrointest Endosc 55: 307-314, 2002.

24. Toyonaga T, Mani M, Fujita T, et al: Retrospective study of technical aspects and complications of endoscopic submucosal dissection for laterally spreading tumors of the colorectum. Endoscopy 42: 714-722, 2010.

25. Sakamoto N, Beppu K, Matsumoto K, et al: 'Loop Clip', a new closure device for large mucosal defects after EMR and ESD. Endoscopy 40: E97-E98, 2008.

26. Yosuke O, Yutaka S, Taku S, et al: New closure technique for large mucosal defects after endoscopic submucosal dissection of colorectal tumors (with video). Gastrointest Endosc 75: 663-667, 2012.

27. Voermans RP, Vergouwe F, Breedveld P, et al: Comparison of endoscopic closure modalities for standardized colonic perforations in a porcine colon model. Endoscopy 43: 217-222, 2011.

28. Schurr MO, Hartmann C, Ho CN, et al: An over-the-scope clip (OTSC) system for closure of iatrogenic colon perforations: results of an experimental survival study in pigs. Endoscopy 40: 584-588, 2008

29. Kirschniak A, Kratt T, Stuker D, et al: A new endoscopic overthe-scope clip system for treatment of lesions and bleeding in the GI tract: first clinical experiences. Gastrointest Endosc 66: 162-167, 2007.

30. von Renteln D, Vassiliou MC and Rothstein RI: Randomized controlled trial comparing endoscopic clips and over-the-scope clips for closure of natural orifice transluminal endoscopic surgery gastrotomies. Endoscopy 41: 1056-1061, 2009.

31. Albert JG, Friedrich-Rust M, Woeste G, et al: Benefit of a clipping device in use in intestinal bleeding and intestinal leakage. Gastrointest Endosc 74: 389-397, 2011.

32. Seebach L, Bauerfeind P and Gubler C: 'Sparing the surgeon': clinical experience with over-the-scope clips for gastrointestinal perforation. Endoscopy 42: 1108-1111, 2010. 